\title{
Alignment of Goals and Perceptions of Computing Predicts Students' Sense of Belonging in Computing
}

\author{
Colleen Lewis \\ Harvey Mudd College \\ Claremont, CA \\ lewis@cs.hmc.edu \\ Jonathan Raygoza \\ Harvey Mudd College \\ Claremont, CA \\ jraygoza@hmc.edu
}

\author{
Paul Bruno \\ University of Southern California \\ Los Angeles, CA \\ pbruno@usc.edu \\ Julia Wang \\ Harvey Mudd College \\ Claremont, CA \\ jjwang@hmc.edu
}

\begin{abstract}
The lack of diversity has been a troubling issue for the field of computing. As the industry continues to expand, it is imperative that diversity levels in computing fields increase to fill the ever-growing number of computing jobs and to represent the technological needs of a diverse populace. Our research seeks to better understand the factors that lead to this lack of diversity by analyzing data from computing majors from colleges within the United States and Canada. Our study reveals that students of different demographic backgrounds have varying levels of communal values, which, depending on how they perceive the affordance of computing to fulfill such values, predict their sense of belonging in computing, which is an important predictor of student retention.
\end{abstract}

\section{KEYWORDS}

belonging, diversity, inclusion, social impact, communal goals

\section{ACM Reference Format:}

Colleen Lewis, Paul Bruno, Jonathan Raygoza, and Julia Wang. 2019. Alignment of Goals and Perceptions of Computing Predicts Students' Sense of Belonging in Computing. In International Computing Education Research Conference (ICER '19), August 12-14, 2019, Toronto, ON, Canada. ACM, New York, NY, USA, 9 pages. https://doi.org/10.1145/3291279.3339426

\section{INTRODUCTION}

Computing fields suffer from a lack of diversity [10, 19, 20, 22, 26, $28,37]$. This lack of diversity is problematic for a number of reasons. First, the computing industry is one of the fastest growing industries. For example, at current graduation rates, by the year 2020 the U.S. will only be able to fill $30 \%$ of domestic computing jobs with U.S. graduates [8]. Making computing more accessible to individuals from a wider range of backgrounds will increase the

Permission to make digital or hard copies of all or part of this work for personal or classroom use is granted without fee provided that copies are not made or distributed for profit or commercial advantage and that copies bear this notice and the full citation on the first page. Copyrights for components of this work owned by others than the author(s) must be honored. Abstracting with credit is permitted. To copy otherwise, or republish, to post on servers or to redistribute to lists, requires prior specific permission and/or a fee. Request permissions from permissions@acm.org.

ICER '19, August 12-14, 2019, Toronto, ON, Canada

(C) 2019 Copyright held by the owner/author(s). Publication rights licensed to ACM. ACM ISBN 978-1-4503-6185-9/19/08 ..\$15.00

https://doi.org/10.1145/3291279.3339426 total number of computing graduates who may enter the computing workforce. Furthermore, as technology continues to expand, diversity of thought is vital for innovation [24]. Creating useful products for society requires a diverse group of developers who understand the various issues plaguing society $[6,31]$.

Diekman and colleagues have argued that women are less interested in science, technology, engineering, and math (STEM) because they do not believe computing will allow them to meet their personal goals $[7,13,15,16]$. They have developed an empirical basis for goal congruity theory, which posits that students' personal goals and their perceived ability to fulfill those goals within the field (i.e., goal affordances) need to be aligned in order for student so be interested in a particular field $[7,13,15,16]$. Put simply, when one does not believe they will be able to meet their personal goals in a given career path, they are unlikely to pursue that career path.

Specifically, Diekman focuses on alignment between the affordances of STEM and students' communal goals, or a desire to work with and to the benefit of others. Of relevance to the current work, underrepresented groups in computing (e.g., women; students of color; first generation college students) ${ }^{1}$ tend to hold strong communal goals [1, 13, 15, 33, 34]. However, technical fields like computing are believed to afford low opportunity to be communal compared to other fields, such as the social sciences or life sciences (see [13, 34]).

For computing majors, the dissonance between their goals and their perception of the goal affordances of computing may lead to a lower sense of belonging, which has been linked to higher likelihoods of leaving computing-related fields [3, 36]. This is particularly important to the field of computing since it has been noted that certain underrepresented groups are more likely than others to leave a computing major $[11,18]$.

We analyze survey responses from 5,821 students pursuing a computing-related undergraduate degree in the U.S. from over 100 institutions. As with prior work, we find that students from underrepresented groups are both more likely to have communal (rather than individualistic) goal orientations and to have a weaker sense of belonging with computing. Consistent with theoretical predictions, we find that among students majoring in computing, communal goal orientations negatively predict sense of belonging in computing and that this relationship is moderated by the extent to which

${ }^{1}$ Of course, these groups are not independent; students may have several underrepresented identities at once (e.g., women of color). 
students perceive computing as affording opportunities to advance communal goals. Specifically, the relationship between communal goals and sense of belonging in computing is more strongly negative among students who perceive computing as having fewer affordances for advancing communal goals. These relationships are robust to controlling for students' demographic characteristics and unobserved differences between undergraduate institutions, suggesting that better aligning instruction and cultures in computing departments to students' goals may be a promising means of promoting equitable access to computing education and careers.

\section{PREVIOUS RESEARCH}

Past research has identified that a match between a student's personal goals and their perception of the affordances of a STEM field is a strong predictor of interest in STEM fields $[1,13,15,33,34]$. The goals of communion and agency have been highlighted as being particularly important human motivations [2]. Communal goals relate to the desire to serve humanity and work for the betterment of others. Communal goals are contrasted with agentic goals that relate to the desire for achievement, independence, self-promotion, and working for one's own betterment ${ }^{2}$ [2].

Previous studies have found demographic differences in endorsement of communal goals and differences in the extent to which different fields are perceived as having communal goal affordances (i.e., as offering the opportunity to achieve communal goals). For example, women, first-generation college students ${ }^{3}$, and underrepresented minority ${ }^{4}$ students have been more likely to endorse communal goals across many studies [1, 13, 15, 21, 33, 34]. At the same time, previous research has documented a lower perception of computing as having communal goal affordances compared to other fields $[13,34]$.

Studies have shown that students are less interested in fields that they do not perceive as offering affordances for the goals they hold $[1,13,15,33,34]$. In particular, these studies have proposed that the goal-affordance mismatch between women and STEM fields as one explanation for the gender gap in STEM fields and refer to this explanation as "goal-congruity theory" [7, 13, 15].

Our study focuses on computing, which claims some of the largest disparities among gender and race within STEM fields [10, $22,26,28,37]$. Like previous work, we investigate differences in communal goals by gender, but we expand on previous work by also investigating differences by race and first-generation status.

Additionally, we focus on sense of belonging among current majors rather than interest in the field because belonging is an important predictor of important educational outcomes [5, 23, 27] and a focus on current computing majors may lead to clearer implications for tertiary computing instructors.

\section{RESEARCH QUESTIONS}

In the current work, we use goal-congruity theory to better understand underrepresented students' experiences in the computing

\footnotetext{
${ }^{2}$ Previous research includes general [13] and CS-specific [7] examples.

${ }^{3}$ First-generation college students refers to students who are the first in their family to attend college

${ }^{4}$ Underrepresented minority, often abbreviated URM, refers to students from racial and ethnic groups who are underrepresented in STEM relative to their proportion of the population [35]
}

major. We first run a set of preliminary analyses to assess the following: (RQ1a) the degree to which underrepresented versus wellrepresented students endorse communal goals for their careers, and (RQ1b) underrepresented versus well-represented students' sense of belonging in computing.

We then run our primary analyses to directly test goal-congruity theory. We specifically assess: (RQ2a) the degree to which students' communal goals and their perceptions of whether or not computing can be used to fulfill communal goals (i.e., their perceived communal affordances of computing) are related to their sense of belonging in computing, (RQ2b) whether the relationship between students' strong communal goal orientations and their sense of belonging in computing is contingent on the degree to which students believe computing careers afford the opportunity to be communal, and (RQ2c) the extent to which the observed relationships between students' communal goals, perceived communal affordances of computing, and their sense of belonging in computing are biased by underlying factors of gender, race, first generation status, and institution.

\section{DATA}

\subsection{Sample}

In the fall of 2016, survey data were collected from 7,300 undergraduate students by the Center for Evaluating the Research Pipeline (CERP), which is part of the Computing Research Association (CRA). CERP distributed the survey in two ways. First, CERP sent the survey to computing departments at 104 universities and colleges across the United States. Department chairs and/or administrative staff within computing departments then distributed the survey to students at their respective institutions. Second, CERP distributed the survey directly to computing students who had participated in the survey in a previous year and had consented to be contacted again the following year. Respondents were entered in a raffle for a $\$ 100$ USD gift card.

Given that we were interested in students' sense of belonging and persistence in a computing major, non-computing majors were excluded from our analyses. The analytic sample consists of 5,821 students, approximately one-third of whom are female. Due to small sample sizes, our analysis was limited to students who identified as male or female ${ }^{5}$.

As shown in Table 1 the large majority of included respondents are White ${ }^{6}(55 \%)$ or Asian ${ }^{7}$ (34\%); however, because of the large sample size, even the small proportions of Black $^{8}(4 \%)$ and Lat$\operatorname{inx}^{9}(6 \%)$ students include 218 and 323 students, respectively. Due

\footnotetext{
${ }^{5}$ Our analysis excluded students who selected "Gender-queer/non-conforming" or "Something else."

${ }^{6}$ We refer to students who selected "Caucasian/European/White" as "White"

${ }^{7}$ We refer to students who selected "East Asian (e.g., Chinese, Japanese, Korean)," "Southeast Asian (e.g., Cambodian, Vietnamese, Hmong, Filipino)," "South Asian (e.g., Indian, Pakistani, Nepalese, Sri Lankan)," or "Other Asian" as "Asian"

${ }^{8}$ We refer to students who selected ""African American/African/Black"" as "Black" ${ }^{9}$ We refer to students who selected "Caribbean/Puerto Rican," "Mexican American/Chicano," or "Mexican American/Chicano" as "Latinx." We use Latinx rather than Latino/a to avoid the assumption that someone identifies with only one of two genders. In the paper, we refer to "Latinx" as a racial group, but in the U.S. Latinx is more likely to be treated as ethnicity that is distinct from race. Students who selected more than one option were classified as multiracial and removed from our sample.
} 
to small sample sizes, our analysis was limited to students who identified as White, Asian, Black, or Latinx ${ }^{10}$.

Eleven percent of the students are first-generation college students, who in response to the question What is the highest level of education attained by your any of your parent(s)/guardian(s)?, selected Less than high school, High school graduate, GED, or Some college (no degree earned), or Associate's degree.

With institutions classified based upon the highest-degree awarded $84 \%$ of respondents were from $\mathrm{PhD}$ granting institutions, $10 \%$ were from Masters-granting institutions, $6 \%$ were from Bachelors-granting institutions, and less than $1 \%$ were from Associates-degree granting institutions.

Table 1: Summary of participant demographics.

\begin{tabular}{lcc}
\hline & Percent & $\mathrm{N}$ \\
\hline White & 55 & 5152 \\
Asian & 34 & 5152 \\
Black & 4 & 5152 \\
Latinx & 6 & 5152 \\
Female & 33 & 5136 \\
First Generation & 11 & 4869 \\
\hline
\end{tabular}

\subsection{Measures}

In addition to the demographic data from the survey, students were asked about their goals and values, their perceptions of computing, and their experiences in computing. Survey responses from these later topics were used in our analysis as described below.

4.2.1 Sense of Belonging in Computing. Sense of belonging in computing was measured by a composite measure consisting of the following three survey items (Cronbach's alpha $=0.80^{11}$ ): I feel like I belong in computing, I see myself as a computing person, and I feel like an outsider in the computing community (reverse coded). The survey stated, "Rate the degree to which you disagree or agree with the following statements:" with the options (1) Strongly disagree, (2) Disagree, (3) Neither disagree nor agree, (4) Agree, (5) Strongly agree. We created an aggregate, sense-of-belonging measure by averaging the three responses. If all of the three items were unranked, the student did not receive a value for the sense-of-belonging aggregate. If only a subset of the three items were unranked by a student, the mean of the ranked items was used.

4.2.2 Communal Goals. The strength of communal goals was measured by asking students to respond to the following: How important to you is it that your future career allows you to do each of the following? give back to my community, have a social impact, serve humanity, and help others. Each item was ranked by students on the following scale: (1) not at all important, (2) slightly important, (3) somewhat important, (4) quite a bit (5) extremely important. To construct the sense of communal goals, the mean of the four items was taken with missing data handled as described above. An identical process

\footnotetext{
${ }^{10}$ Our analysis excluded students who selected "American Indian/Alaska Native," "Native Hawaiian/Pacific Islander," "Arab/Middle Eastern," or "Something else."

${ }^{11}$ Even though these items have high internal reliability, we do not have independent verification of their validity, but believe they have high face validity.
}

was used to construct communal goals aggregate, such that only students that did not respond to any of the relevant survey items in the aggregate did not receive a score for that aggregate. These four items had high internal reliability (Cronbach's alpha $=0.87$ ).

4.2.3 Communal Goal Affordances. The following item was used to measure communal goal affordances: In your opinion, to what extent would a career in computing allow you to serve humanity? This item was ranked using the following scale: (1) not at all, (2) a little, (3) somewhat, (4) quite a bit, (5) very much. Summary statistics for all survey items and composite measures are shown in Table 2.

Table 2: Summary statistics for measures.

\begin{tabular}{lccc}
\hline & Mean & SD & $\mathrm{N}$ \\
\hline I belong in computing & 3.98 & 1.01 & 5807 \\
I feel like an outsider in the & 2.44 & 1.20 & 5818 \\
$\quad$ & & & \\
$\quad$ I see myself as a computing person & 4.12 & 0.93 & 5813 \\
Sense of Belonging & 3.89 & 0.89 & 5821 \\
Goal: Giving back to community & 3.41 & 1.07 & 5813 \\
Goal: Social impact & 3.46 & 1.13 & 5810 \\
Goal: Serve humanity & 3.36 & 1.14 & 5812 \\
Goal: Help others & 3.81 & 1.02 & 5801 \\
Communal Goals & 3.51 & 0.92 & 5821 \\
Perceived Communal Affordance & 3.64 & 0.99 & 5821 \\
\hline
\end{tabular}

Bold text indicates an aggregate measure.

\section{METHODS}

The analysis below proceeds in two stages. First, to answer RQ1, ANOVA methods are used to confirm that our survey data includes the relationships demonstrated in prior literature between students' demographic characteristics, their goal orientations, and their perceptions of computing. Second, we employ multiple regression to answer RQ2.

\subsection{Regression Models}

In our preferred specification, we estimate a model of the form shown in Equation 1.

Equation 1. Final regression model to address RQ2c.

$$
\begin{array}{r}
\text { belonging }_{\text {is }}=\beta_{0}+\beta_{1} \text { goal }_{\text {is }}+\beta_{2} \text { afford }_{\text {is }}+\beta_{3} \text { goal }_{\text {is }} * \text { afford }_{\text {is }}+ \\
\beta_{4} \text { female }_{i s}+\beta_{5} \text { asian }_{i s}+\beta_{6} \text { black }_{i s}+\beta_{7} \text { latinx }_{i s}+ \\
\beta_{8} \text { firstgen }_{i s}+\delta_{s}+\epsilon_{i s}
\end{array}
$$

- belonging is our outcome of interest - sense of belonging in computing for student $i$ in school $s$ (see Section 4.2.1),

- goal is the measure of each student's communal goal orientation (see Section 4.2.2), and

- afford is the measure of the extent to which a student perceives computing as affording opportunities to advance communal goals (see Section 4.2.3).

We include the interaction of goal and afford because we hypothesize that the relationship between goal orientation and sense of 
belonging is due in part to incongruence between students' goal orientations and their perceptions of the affordances of computing. $\hat{\beta}_{3}$ will therefore capture the extent to which the relationship between students' goal orientations and their sense of belonging varies depending on their perceptions of computing's communal goal affordances.

As with determining any causal relationship, we expect that there are factors other than communal goals and perceptions of computing's communal goal affordances that might explain the variation in sense of belonging among students. For instance, it is possible that students' senses of belonging are related to factors, like discrimination, that are also associated with their goal orientations. Additionally, students may sort to schools - and thus computing departments - on the basis of factors related to both their goal orientation and their expected sense of belonging. For example, this would be the case if schools with reputations for humanitarian cultures attract students with stronger communal goal orientations. Because these factors are known predictors of both communal goals and sense of belonging in computing, they could be a possible source of bias when examining the relationships among communal goals, communal goal affordances, and sense of belonging. We therefore also include a series of dummy variables indicating whether students are female (reference group: male); Asian, Black, or Latinx (reference group: White students); or firstgeneration college students, and a set of school fixed effects, $\delta_{s}{ }^{12}$ $\epsilon$ is an error term.

\subsection{Hypotheses}

We predict that the coefficient $\hat{\beta}_{3}$ will be significant and positive, indicating that communal goal orientation is less negatively related to sense of belonging in computing for students who perceive computing as offering opportunities to advance communal goals. Stated another way, we predict that perceptions of computing's communal goal affordances are more positively related to sense of belonging for students with stronger communal goal orientations.

\subsection{Additional Details of Models}

Our hypothesis about the relationships between communal goals, perceptions of computing's goal affordances, and sense of belonging in computing is causal, but given the cross-sectional nature of our data the coefficients we estimate cannot be given a strong causal interpretation for at least two reasons. First, we cannot rule out the possibility of reverse causality (e.g., if students' sense of belonging in computing is somehow determinative of their goal orientations). Second, other factors, such as discrimination faced by students from underrepresented groups, may be related to both sense of belonging and either students' goal orientations or their perceptions of computing's affordances. If not included in the model, these omitted variables will bias our estimates of the true effect of students' goal orientations, their perceptions of computing, or both. The research described above suggests that such factors exist; indeed, they motivate the present study. Specifically, if students from underrepresented groups (e.g., women) also tend to have stronger communal goal orientations, then simple regressions estimating

\footnotetext{
${ }^{12}$ These fixed effects can be thought of as a dummy variable for each school.
}

the relationship between goal orientation and belonging will combine the true effect of goal orientation with the other effects of being in underrepresented groups, biasing the resulting estimates. This motivates our use in Equation 1 of the demographic indicators described above.

One concern with controlling for student demographic characteristics is that if students from underrepresented groups have lower belonging because of their goal orientations, including the demographic controls will tend to mask the effect of communal goal orientations because they explain a shared portion of the variation in belonging. The decision to include the demographic controls therefore hinges on the relative importance of other mechanisms by which demographic characteristics might affect sense of belonging in computing. Because we assume that students from underrepresented groups will have a large number of experiences independent of their goal orientations but relevant to their sense of belonging we consider it necessary to control for these demographic factors. However, we acknowledge that this may tend to make our estimates somewhat conservative should that assumption be incorrect.

Controlling for observable student characteristics is valuable when possible, but students may differ for many unobserved reasons as well. As a final step in attempting to mitigate potential omitted variable bias we exploit the fact that students in our sample are nested within schools. This allows us to include in our model a set of school fixed effects to control for average differences between schools. This allows for the possibility that students sort to schools in ways that are related both to their sense of belonging and their goal orientations or perceptions of computing. Of course, even controlling for unobserved heterogeneity between schools may not control for all relevant factors, and thus the estimates resulting even from this model will not have a clear causal interpretation. Nevertheless, our hypothesis is causal and has potentially important practical implications so it is useful to test the sensitivity of our estimates to these additional controls, and so we estimate models with and without these additional controls.

To facilitate interpretation, our survey measures of interest perceived communal goal affordances, mean communal goal orientation, and sense of belonging - are standardized to have a mean of zero and standard deviation of one across all students in the sample.

As a final methodological note, we cluster our standard errors on schools in all of our multiple regression models. The need for clustered standard errors is another consequence of the nested nature of our survey data. Classical standard errors are calculated on the assumption that observations are independent of one another. This assumption is dubious when observed units - in this case, students - are clustered together (e.g., in schools) and may therefore have correlated error terms. Because each additional observation from a particular school is likely to provide less new information than an observation from a previously-unoberserved school, conventional standard errors will be too small. ${ }^{13}$ Clustering standard errors on schools therefore has the consequence of (potentially) increasing our standard errors and our confidence intervals, and thus reducing our statistical power. However, this allows us to relax

\footnotetext{
${ }^{13}$ Heteroskedasticity-robust standard errors may also be too small if they are not also cluster-robust.
} 
the assumption that observations within schools are independent of one another, providing more credible estimates of precision.

\section{RESULTS}

\subsection{RQ1a: Differences in Communal Goals}

RQ1a : Do underrepresented groups versus well-represented groups differ in the degree to which they hold communal goals for their future careers?

We ran a series of between subjects one-way Analyses of Variance (ANOVAs) to determine if there were significant differences in communal goals across gender, race, and/or first-generation status. Summary statistics appear in Figure 1 and Table 3.

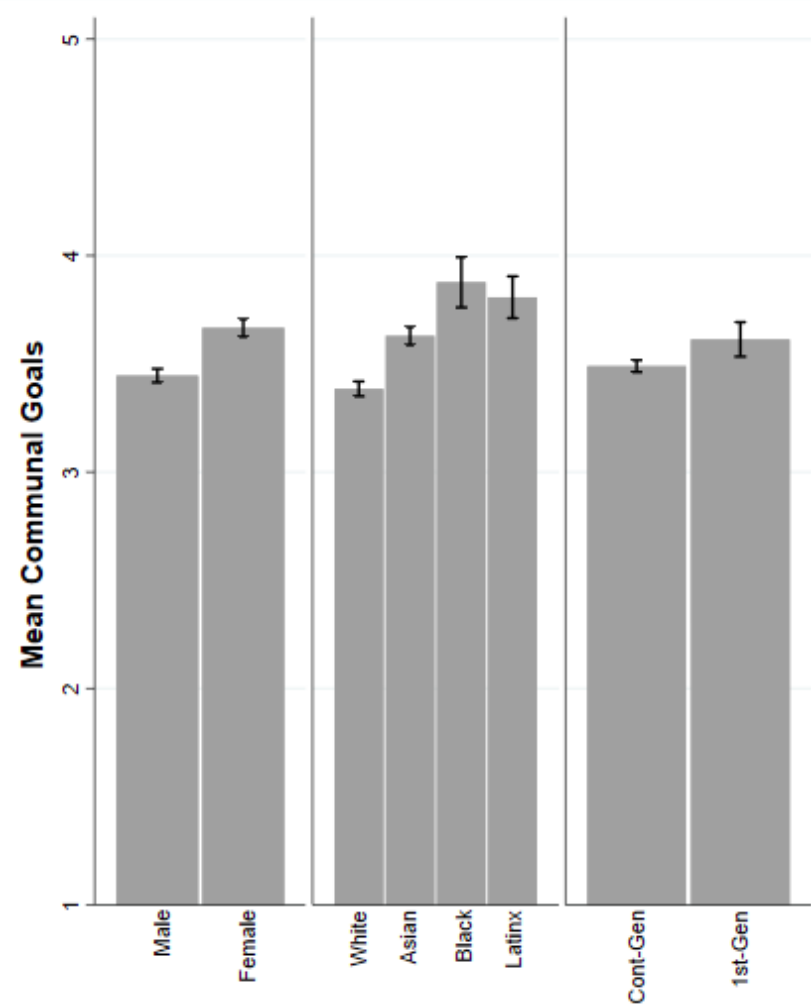

Figure 1: Mean Communal Goals by Group

These ANOVAs revealed that women tend to have higher communal goals than men $(\mathrm{F}(1,5134)=65.97, p<0.0001)$. There was also a significant effect of race $(\mathrm{F}(3,5148)=51.39, p<0.0001)$ on communal goal endorsement. Post-hoc Dunnett t-tests with White students as the control group then revealed that Asian, Black, and Latinx students had significantly higher communal goal endorsement than White students (for each $p<0.001$ ). First-generation students tended to have higher communal goals than continuing-generation students $(\mathrm{F}(1,4867)=8.36, p<0.005)$.

\subsection{RQ1b: Differences in Sense of Belonging}

RQ1b : Do underrepresented groups versus well-represented groups differ in the degree to which they report a sense of belonging in computing?

We ran another series of between subjects one-way ANOVAs to determine if there were significant differences in sense of belonging in computing across gender, race, or first-generation status. Summary statistics appear in Figure 2 and Table 3.

These ANOVAs revealed that women had a lower sense of belonging in computing than men $(\mathrm{F}(1,5134)=596.97, p<0.0001)$. There was also a significant effect of race $(\mathrm{F}(1,5148)=36.75, p<0.0001)$ on sense of belonging in computing. Post-hoc Dunnett t-tests with White students as the control group then revealed that Asian and Black students had a significantly lower sense of belonging in computing than White students (for each $p<0.001$ ). There was no significant effect on sense of belonging in computing for identifying as Latinx $(p=0.81)$ or as a first generation student compared to a continuing generation student $(p=0.26)$.

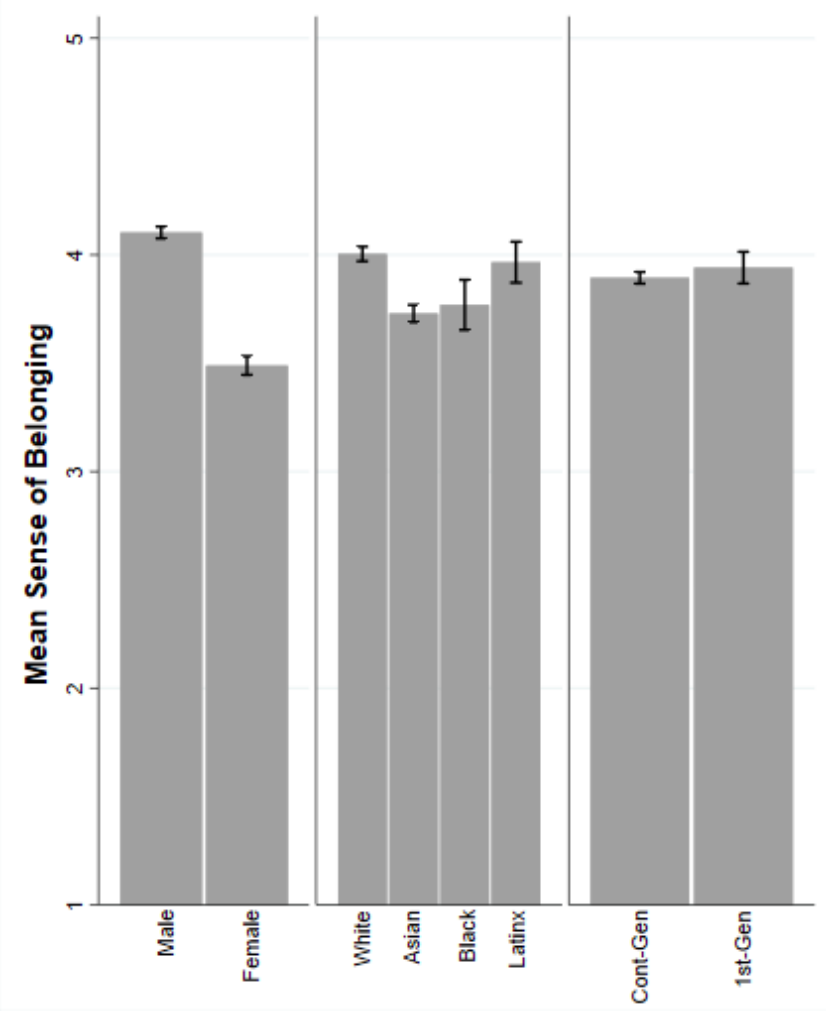

Figure 2: Mean Perceived Sense of Belonging by Group

\subsection{RQ2a: Predicting Sense of Belonging}

RQ2a : Do the level of students' communal goals and the degree to which students perceive computing as affording ample opportunities to advance communal goals predict their sense of belonging in computing? 
Table 3: Summary Statistics by Group

\begin{tabular}{lccccccccc}
\hline & \multicolumn{3}{c}{ Sense of Belonging } & \multicolumn{3}{c}{ Communal Goals } & \multicolumn{3}{c}{ Affordance of Computing } \\
\hline & Mean & SD & N & Mean & SD & N & Mean & SD & N \\
\hline Male & 4.10 & 0.81 & 3440 & 3.45 & 0.94 & 3440 & 3.64 & 1.01 & 3440 \\
Female & 3.49 & 0.91 & 1696 & 3.67 & 0.86 & 1696 & 3.68 & 0.95 & 1696 \\
\hline White & 4.00 & 0.92 & 2859 & 3.38 & 0.93 & 2859 & 3.60 & 0.99 & 2859 \\
Asian & 3.73 & 0.85 & 1752 & 3.63 & 0.89 & 1752 & 3.65 & 0.98 & 1752 \\
Black & 3.77 & 0.87 & 218 & 3.88 & 0.88 & 218 & 3.99 & 0.92 & 218 \\
Latinx & 3.97 & 0.87 & 323 & 3.81 & 0.89 & 323 & 3.90 & 0.99 & 323 \\
\hline Continuing Generation & 3.89 & 0.90 & 4349 & 3.49 & 0.92 & 4349 & 3.64 & 0.98 & 4349 \\
First Generation & 3.94 & 0.85 & 520 & 3.61 & 0.92 & 520 & 3.68 & 1.05 & 520 \\
\hline
\end{tabular}

Table 4: Regressions Predicting Sense of Fit in Computing

\begin{tabular}{|c|c|c|c|c|}
\hline & A & B & $\mathrm{C}$ & $\mathrm{D}$ \\
\hline $\begin{array}{l}\text { Communal } \\
\text { Affordances }\end{array}$ & $\begin{array}{c}0.21^{* * *} \\
(0.02)\end{array}$ & $\begin{array}{c}0.22^{* * *} \\
(0.02)\end{array}$ & $\begin{array}{c}0.20^{* * *} \\
(0.02)\end{array}$ & $\begin{array}{c}0.19^{* * *} \\
(0.02)\end{array}$ \\
\hline $\begin{array}{l}\text { Communal } \\
\text { Goals }\end{array}$ & $\begin{array}{c}-0.13^{* * *} \\
(0.02)\end{array}$ & $\begin{array}{c}-0.13^{* * *} \\
(0.02)\end{array}$ & $\begin{array}{c}-0.07^{* * *} \\
(0.01)\end{array}$ & $\begin{array}{c}-0.07^{* * *} \\
(0.01)\end{array}$ \\
\hline Interaction & & $\begin{array}{c}0.05^{* * *} \\
(0.01)\end{array}$ & $\begin{array}{c}0.04^{* * *} \\
(0.01)\end{array}$ & $\begin{array}{l}0.03^{* *} \\
(0.01)\end{array}$ \\
\hline Female & & & $\begin{array}{c}-0.59^{* * *} \\
(0.03)\end{array}$ & $\begin{array}{c}-0.58^{* * *} \\
(0.03)\end{array}$ \\
\hline Black & & & $\begin{array}{l}-0.21^{*} \\
(0.08)\end{array}$ & $\begin{array}{c}-0.32^{* * *} \\
(0.07)\end{array}$ \\
\hline Latinx & & & $\begin{array}{l}-0.06 \\
(0.06)\end{array}$ & $\begin{array}{l}-0.16^{*} \\
(0.07)\end{array}$ \\
\hline Asian & & & $\begin{array}{c}-0.18^{* * *} \\
(0.03)\end{array}$ & $\begin{array}{c}-0.16^{* * *} \\
(0.04)\end{array}$ \\
\hline First Gen & & & $\begin{array}{c}0.05 \\
(0.04)\end{array}$ & $\begin{array}{c}0.01 \\
(0.04)\end{array}$ \\
\hline Constant & $\begin{array}{c}3.89^{* * * *} \\
(0.02)\end{array}$ & $\begin{array}{c}3.86^{* * *} \\
(0.02)\end{array}$ & $\begin{array}{c}4.15^{* * *} \\
(0.03)\end{array}$ & $\begin{array}{c}4.15^{* * *} \\
(0.02)\end{array}$ \\
\hline Institution FE & No & No & No & Yes \\
\hline$N$ & 5815 & 5815 & 4738 & 4695 \\
\hline Schools & 183 & 183 & 170 & 127 \\
\hline Adj. R-sq & 0.04 & 0.05 & 0.15 & 0.17 \\
\hline
\end{tabular}

Table 4 presents results of regressions predicting sense of belonging in computing. As shown in Model A, both communal goals and perceptions of computing's communal goal affordances predict sense of belonging in computing. These relationships are both statistically and practically significant. For example, a one standard deviation increase in communal goal orientation is associated with a decline in sense of belonging of approximately 13 percent of a standard deviation.

\subsection{RQ2b. Goal-congruity interaction}

RQ2b : Is this relationship between sense of belonging and perceptions of computing's communal affordances stronger for students with high communal goals than students with low communal goals?

Consistent with our hypothesis, these predictors exhibit a significant and positive interaction (Model B). In the presence of the interaction term the interpretation of the coefficients on the uninteracted terms changes; because they are mean centered, they represent the relationship between each predictor and sense of belonging for students with the average value of the other predictor. Thus, Model B indicates that for students with "average" perceptions of computing's communal goal affordances, stronger communal goal orientations are associated with lower levels of belonging. However, the positive interaction term implies that that relationship is less negative for students who perceive greater communal affordances for computing. ${ }^{14}$ These relationships are illustrated in Figure 3.

\subsection{RQ2c: Controlling for Demographics and Institution}

RQ2c : To what extent are the relationships among communal goals, communal goal affordances, and sense of belonging in computing biased by race, gender, first generation status, and institutional differences?

As discussed above, the coefficients in Model B will capture the true effect of students' goals and affordance perceptions on their

\footnotetext{
${ }^{14}$ Alternatively, and equivalently, for students with average communal goal orientations, perceptions of computing's communal affordances are associated with higher levels of belonging, and that relationship increases in magnitude for students with stronger communal goal orientations.
} 
sense of belonging, but will also capture the effects on belonging of any other factors not included in the regression if those factors are also correlated with students' goals and affordance perceptions. Model C therefore controls for student demographic characteristics, which we demonstrated above to be positively related to communal goal orientations (see Section 6.1) and negatively related to sense of belonging (see Section 6.2). As expected, much of the relationship between students' communal goal orientation and their sense of belonging can be explained by their demographic characteristics; the relationship becomes substantially less negative, shrinking in magnitude by almost half for students with average perceptions of computing's communal affordances. The magnitude of the interaction also shrinks somewhat, but retains its significance and qualitative interpretation: the relationship between communal goals and sense of belonging is less negative for students who perceive computing as having affordances for advancing communal goals.

Model D presents results from our preferred specification (Equation 1), including a school fixed effect to control for unobserved differences between schools. The coefficients of interest shrink only slightly in magnitude, suggesting that while schools do differ slightly in their students' average levels of belonging (the adjusted R-squared increases from .15 to .17), these differences are not closely related to differences in students' goal orientations or perceptions of computing's affordances. ${ }^{15}$ Even within schools and controlling for their gender, race, and first-generation status, students' communal goal orientations negatively predict their sense of belonging and this relationship is moderated by the extent to which they view computing as offering affordances for achieving communal goals.

\section{DISCUSSION}

The findings from this study help us examine the underlying factors that contribute to the lack of diversity in computing fields. Our study reveals that students with high communal goals tend to have a lower sense of belonging in computing than their peers with low communal goals. Perceptions of communal affordances, on the other hand, exhibit a positive relationship with sense of belonging in computing, such that students who perceive computing as having more communal goal affordances tend to have a higher sense of belonging in computing compared to their peers who perceive computing as having fewer communal goal affordances. While communal goals are negatively related to belonging, this relationship is mitigated for students who perceive computing as affording ample opportunities to advance communal goals.

Through our conditional effects testing, we found that the communal goal affordances of computing seem to matter more for students with high communal goals compared to students with low communal goals. There was a larger increase in sense of belonging for students with high communal goals than for their peers with low communal goals. These results provide further evidence for the importance of a match between a student's goals and their

\footnotetext{
${ }^{15}$ Though beyond the scope of this paper to investigate, it is noteworthy that the coefficients on the demographic predictors in some cases change more substantially. This may indicate that computing students sort to schools on the basis of some charac teristics, such as race, in ways that may obscure the extent to which their backgrounds affect their sense of belonging. For instance, Latinx students may enroll in schools or computing departments more effective at fostering belonging in general, but may nevertheless have below-average belonging within whatever institution they attend.
}

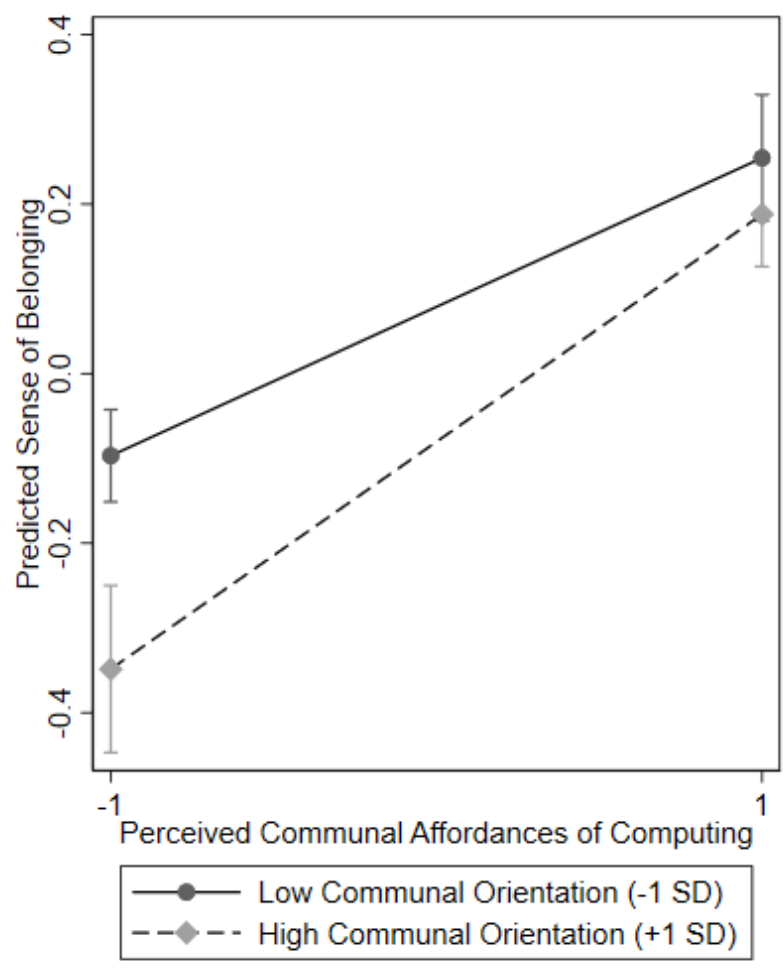

Figure 3: Interaction between Communal Goals and Communal Affordances

perceived affordances of computing in contributing to their sense of belonging in computing fields.

This is particularly problematic for computing fields since, as we noted in our confirmatory analyses, students who belong to underrepresented groups in computing tend to have higher communal goal endorsement on average. In particular, in our sample, we found that women tend to have higher communal goals than men, and Black and Latinx students tend to have higher communal values than their White peers.

The significance of these findings is amplified when we take into account the results of our final regression that examines the effects of communal goals, communal goal affordances, and goalaffordance match while controlling for demographic variables of gender, race, and first-generational status. Because the interaction term is significant even when taking into account the demographic information of students, our analyses show how a goal-affordance match may have significant impact on student's sense of belonging in computing above and beyond the effects of their identity. This mismatch between these students' goals and their perceived affordances of computing conduces a lower sense of belonging in computing which can contribute to lower rates of retention, and therefore may partially explain the underrepresentation of these particular groups in computing fields. 


\section{LIMITATIONS AND FUTURE WORK}

The data used for this study were cross sectional, so we cannot demonstrate causality for our model which predicts students' sense of belonging in computing based on communal goals and their perceived communal goal affordances of computing. However, our analyses do strongly support our proposed model by controlling for a number of possible confounding factors in this relationship. Further research examining the relationship between communal goals, communal goal affordances, and sense of belonging in computing fields could control for other variables that often predict communal values (e.g., religion) or variables that may predict belonging (e.g., self-efficacy).

Moreover, an experimental study could be conducted to establish a clearer causal relationship among communal goals, perceived communal goal affordances, and sense of belonging in computing. Such a study might involve implementing intervention programs at schools to increase the perceived communal goal affordances of computing for students and collecting longitudinal data to determine whether the programs are successful in increasing students' perceived communal goal affordances, and if so, whether that affects students' sense of belonging within computing.

While the rest of our latent variables were created through confirmatory factor analysis and computed as the aggregate of multiple survey questions, our variable for perceived communal goal affordances of computing is created from a single measure obtained from one survey response. Future research delving into the effects of perceived communal goal affordances in computing should look into constructing a more rigorous measure of the variable by using an aggregate of several questions to gauge the level of perceived goal affordances among students.

Our study examined gender, first-generation status, and four racial groups, but a growing body of literature shows that examining dimensions of people's identities in isolation ignores important ways in which these identities interact $[12,29,30]$. This compounds an existing problem with heterogeneity within racial groups. Additionally, due to the low number of respondents who identified with certain racial groups (i.e. Native American, Native Hawaiian/ Pacific Islander, Middle Eastern) and students classified as multiracial, we were unable to include them in our analyses.

\section{CONCLUSION}

There are several contributions to theory and research in the current work. First, we test goal-congruity theory by focusing on a specific STEM (Science, Technology, Engineering, and Mathematics) field, computing, which has some of the largest disparities among gender and race within STEM fields [10, 22, 26, 28, 37].

Second, whereas prior research focuses on the influence of goal congruity on non-majors' attitudes towards STEM [13, 15] and enrollment in STEM courses [34], our research focuses on students' persistence in a STEM field. That is, we study the degree to which goal congruity predicts computing majors' sense of belonging in the field. A student's sense of belonging in computing has been a noted predictor of retention in computing $[3,9,36]$. While goal congruity is theorized to be related to individuals' sense of belonging in a given context, we know of no research on goal congruity that has looked specifically at belonging in computing.
Finally, our analyses include a model that controls for schools. This is important because there are many factors that are likely to affect a student's sense of belonging that we cannot directly control for; however, we suspect that students at the same school will share some of these factors. Controlling for school thus takes into account some of these other unobserved differences between students that are not captured by their gender, race, and first generation status. This likely provides more credible estimates of the extent ot which computing majors' sense of belonging in computing is dependent on the alignment between their goal orientations and their perceptions of computing's affordances.

Our research highlights the importance of goal-affordance match on students' sense of belonging in computing fields. Because computing is traditionally perceived as having low levels of communal affordances, the main takeaway from this study is that in order to increase diversity within computing fields, it will likely be helpful to showcase the communal affordances of computing. Shifting perceptions of the goal affordances of computing in this way will allow students with higher communal values feel a greater sense of belonging within computing and make them more likely to stay in the field.

These results are consistent with, and provide additional theoretical motivation for, previous research suggesting that opportunities for communal STEM experiences - such as volunteering, mentoring, and group projects - may be effective for improving students' perceptions of computing, particularly among underrepresented groups $[4,7,25,32]$. They are also consistent with the call from Diekman and colleagues [14] to "align STEM activities with students' values" in addition to challenging stereotypes and encouraging students to believe their ability can grow with effort (i.e., adopt a growth mindset [17]). Our study does not evaluate specific interventions. However, our results suggest that strategies intended to highlight the communal goal affordances of computing, such as explicitly highlighting the contributions of computing to communities' well-being or facilitating community-oriented job placement opportunities for students, could have benefits for participation.

\section{ACKNOWLEDGMENTS}

This work was supported by National Science Foundation grants 1339404 and 1821136. The authors would like to thank Jane Stout, Burçin Tamer, and Heather Wright for their contributions developing and supporting this project.

\section{REFERENCES}

[1] Jill M Allen, Gregg A Muragishi, Jessi L Smith, Dustin B Thoman, and Elizabeth R Brown. 2015. To grab and to hold: Cultivating communal goals to overcome cultural and structural barriers in first-generation college studentsâĂŹ science interest. Translational issues in psychological science 1, 4 (2015), 331.

[2] David Bakan. 1966. The duality of human existence: Isolation and communion in Western man. Beacon Press (MA), MA.

[3] Roy F Baumeister and Mark R Leary. 1995. The need to belong: desire for interpersonal attachments as a fundamental human motivation. Psychological bulletin 117, 3 (1995), 497.

[4] Aimee L Belanger, Amanda B Diekman, and Mia Steinberg. 2017. Leveraging communal experiences in the curriculum: Increasing interest in pursuing engineering by changing stereotypic expectations. Fournal of Applied Social Psychology 47, 6 (2017), 305-319.

[5] Maureen Biggers, Anne Brauer, and Tuba Yilmaz. 2008. Student perceptions of computer science: a retention study comparing graduating seniors with cs leavers. ACM SIGCSE Bulletin 40, 1 (2008), 402-406. 
[6] Kamau Bobb. 2016. Broadening Participation in Computing: A Critical Perspective. ACM Inroads 7, 4 (2016), 49-51.

[7] Bo Brinkman and Amanda Diekman. 2016. Applying the Communal Goal Congruity Perspective to Enhance Diversity and Inclusion in Undergraduate Computing Degrees. In Proceedings of the 47th ACM Technical Symposium on Computing Science Education (SIGCSE '16). ACM, New York, NY, USA, 102-107. https://doi.org/10.1145/2839509.2844562

[8] U.S. Department of Labor Bureau of Labor Statistics. 2018. Occupational Outlook Handbook, Computer and Information Technology Occupations. www.bls.gov

[9] C. Alvarado L. Barker V. Barr T. Camp C. Frieze C. Lewis E. Cannon Mindell L. Limbird D. Richardon M. Sahami E. Villa H. Walker C. Stephenson, A. Derbenwick Miller and S. Zweben. 2018. Retention in Computer Science Undergraduate Programs in the U.S.: Data Challenges and Promising Interventionss.

[10] Tracy Camp. 2012. 'Computing, We Have a Problem \&Hellip;'. ACM Inroads 3, 4 (Dec. 2012), 34-40. https://doi.org/10.1145/2381083.2381097

[11] National Student Clearinghouse Research Center. 2017. Snapshot Report: Firstyear Persistence and Retention. www.bls.gov

[12] Kimberle Crenshaw. 1990. Mapping the margins: Intersectionality, identity politics, and violence against women of color. Stan. L. Rev. 43 (1990), 1241.

[13] Amanda B Diekman, Elizabeth R Brown, Amanda M Johnston, and Emily K Clark. 2010. Seeking congruity between goals and roles: A new look at why women opt out of science, technology, engineering, and mathematics careers. Psychological Science 21, 8 (2010), 1051-1057.

[14] Amanda B Diekman, Emily K Clark, and Aimee L Belanger. 2019. Finding Common Ground: Synthesizing Divergent Theoretical Views to Promote Women's STEM Pursuits. Social Issues and Policy Review 13, 1 (2019), 182-210.

[15] Amanda B Diekman, Emily K Clark, Amanda M Johnston, Elizabeth R Brown, and Mia Steinberg. 2011. Malleability in communal goals and beliefs influences attraction to stem careers: Evidence for a goal congruity perspective. Fournal of personality and social psychology 101, 5 (2011), 902.

[16] Amanda B Diekman, Mia Steinberg, Elizabeth R Brown, Aimee L Belanger, and Emily K Clark. 2017. A goal congruity model of role entry, engagement, and exit Understanding communal goal processes in STEM gender gaps. Personality and Social Psychology Review 21, 2 (2017), 142-175.

[17] Carol S Dweck. 2008. Mindset: The new psychology of success. Random House Digital, Inc., New York, NY, USA.

[18] Rogers Elliott, A Christopher Strenta, Russell Adair, Michael Matier, and Jannah Scott. 1996. The role of ethnicity in choosing and leaving science in highly selective institutions. Research in Higher Education 37, 6 (1996), 681-709.

[19] Nathan L Ensmenger. 2010. Making programming masculine. In Gender codes: Why women are leaving computing, Sally A. Fincher and Anthony V. Robins (Eds.) John Wiley \& Sons, Inc., Hoboken, NJ, USA, Chapter 6, 115-141.

[20] Nathan L Ensmenger. 2012. The computer boys take over: Computers, programmers, and the politics of technical expertise. MIT Press, Cambridge, MA, USA

[21] Allan Fisher, Jane Margolis, and Faye Miller. 1997. Undergraduate women in computer science: experience, motivation and culture. ACM SIGCSE Bulletin 29 , 1 (1997), 106-110.

[22] Diana Franklin. 2013. A practical guide to gender diversity for computer science faculty. Synthesis Lectures on Professionalism and Career Advancement for Scientists and Engineers 1, 2 (2013), 1-81.
[23] Catherine Good, Aneeta Rattan, and Carol S Dweck. 2012. Why do women opt out? Sense of belonging and women's representation in mathematics. fournal of personality and social psychology 102, 4 (2012), 700.

[24] Inga J Hoever, Daan Van Knippenberg, Wendy P Van Ginkel, and Harry G Barkema. 2012. Fostering team creativity: perspective taking as key to unlocking diversity's potential. Journal of applied psychology 97, 5 (2012), 982.

[25] Yasmin Kafai, Jean Griffin, Quinn Burke, Michelle Slattery, Deborah Fields, Rita Powell, Michele Grab, Susan Davidson, and Joseph Sun. 2013. A cascading mentoring pedagogy in a CS service learning course to broaden participation and perceptions. ACM SIGCSE Bulletin 44, 1 (2013), 101-106.

[26] Liana Christin Landivar. 2013. Disparities in STEM employment by sex, race, and Hispanic origin. Education Review 29, 6 (2013), 911-922.

[27] Colleen M. Lewis, Ruth E. Anderson, and Ken Yasuhara. 2016. "I Don’T Code All Day": Fitting in Computer Science When the Stereotypes Don'T Fit. In Proceedings of the 2016 ACM Conference on International Computing Education Research (ICER '16). ACM, New York, NY, USA, 23-32. https://doi.org/10.1145/2960310.2960332

[28] Jane Margolis. 2010. Stuck in the shallow end: Education, race, and computing. MIT Press, Cambridge, MA, USA.

[29] Frieda McAlear, Allison Scott, Kimberly Scott, Jamika Burge, and Sonia Koshy. 2019. Women and Girls of Color in Computing: Exploring Current Trends, Emerging Opportunities, and Strategies for Meaningful Impact. In Proceedings of the 50th ACM Technical Symposium on Computer Science Education (SIGCSE '19). ACM, New York, NY, USA, 1225-1227. https://doi.org/10.1145/3287324.3287341

[30] Maria Ong, Carol Wright, Lorelle Espinosa, and Gary Orfield. 2011. Inside the double bind: A synthesis of empirical research on undergraduate and graduate women of color in science, technology, engineering, and mathematics. Harvard Educational Review 81, 2 (2011), 172-209.

[31] David Rock and Heidi Grant. 2016. Why diverse teams are smarter. Harvard Business Review 4, 4 (2016), 2-5.

[32] Mia Steinberg and Amanda B Diekman. 2017. Elevating Positivity toward STEM Pathways through Communal Experience: The Key Role of Beliefs that STEM Affords Other-Oriented Goals. Analyses of Social Issues and Public Policy 17, 1 (2017), 235-261.

[33] Nicole M Stephens, Stephanie A Fryberg, Hazel Rose Markus, Camille S Johnson, and Rebecca Covarrubias. 2012. Unseen disadvantage: how American universities' focus on independence undermines the academic performance of first-generation college students. Fournal of personality and social psychology 102, 6 (2012), 1178.

[34] Jane G Stout, Victoria A Grunberg, and Tiffany A Ito. 2016. Gender roles and stereotypes about science careers help explain women and menâĂŹs science pursuits. Sex Roles 75, 9-10 (2016), 490-499.

[35] National Center for Education Statistics U.S. Department of Education, Institute of Education Sciences. 2015. Integrated Postsecondary Education Data System (IPEDS): Completions Survey.

[36] Gregory M Walton and Geoffrey L Cohen. 2007. A question of belonging: race, social fit, and achievement. Journal of personality and social psychology 92, 1 (2007), 82.

[37] Jennifer Wang, Hai Hong, Jason Ravitz, and Sepehr Hejazi Moghadam. 2016. Landscape of K-12 Computer Science Education in the U.S.: Perceptions, Access, and Barriers. In Proceedings of the 47th ACM Technical Symposium on Computing Science Education (SIGCSE '16). ACM, New York, NY, USA, 645-650. https: //doi.org/10.1145/2839509.2844628 